\title{
Predicting remaining life of lattice steel transmission tower based on condition assessment and corrosion hazard data
}

\author{
Fathoni Usman ${ }^{1 *}$ and Nor Hazwani Nor Khalid ${ }^{2}$ \\ ${ }^{1}$ Institute of Energy Infrastructure, Universiti Tenaga Nasional, 43000 Kajang, Selangor, Malaysia \\ ${ }^{2}$ Civil Engineering Department, College of Engineering, Universiti Tenaga Nasional, 43000 Kajang, Selangor, Malaysia
}

\begin{abstract}
This paper presents a novel approach for predicting the remaining life of lattice steel transmission towers in Malaysia. The transmission tower components assessment grouped into ground corrosive condition, foundation condition, lattice steel body of the tower, and conductor. Significant and scientific field investigation and visual assessment evaluate the state of the tower. The corrosion hazard, which is a product of climate and air pollution data, is used. Three separated lines and 84 towers were selected with different ages of the tower in service. The Weighing Scoring Method with Analytical Hierarchy Process to impose the weighed factor was used. The survival function analysis is used to predict service life, and the tower remaining life was determined. The paper shows how to use the model to predict the remaining life of a transmission tower and how this can be used to advise maintenance planning.
\end{abstract}

\section{Introduction}

Energy demand and consumption have a significant correlation with population growth. In the case of electricity, the demand is catapulted by the increase of household income which was contributed by $82 \%$ of domestic consumers out of 10.08 million consumers in Malaysia [1,2]. The high voltage transmission towers are among the most precious asset in energy infrastructure spanning from the power plan crossing the urban, rural, and most remote areas to bring electricity to the transmission substations and then distribute to the end consumers. During its service life, the tower subjected to deterioration due to various factors. Environment with different corrosion hazard and the nature of its service and most of the tower located in remote area, the effort to ensure the good condition to provide less power disruption is the utmost. Appropriate maintenance strategies need to be advised and chosen to prevent any failure to the tower and transmission line [3]. The failure will not only cause financial loss but possible loss of life.

There are 24,607 Circuit-km of transmission line, 463 transmission substations, and with the circuit length, 123,290 GWh electricity has transmitted, and 18.808 MWh peak demand in Peninsular Malaysia reported in 2021 [2]. Environmental causes dominated power disruption in Peninsular Malaysia from 2000 to 2016 for $31 \%, 17 \%$ by structural failure, and $40 \%$ caused by conductor problems [1]. Environment load is still not fully understood and overlooked during design and along with the service life [4].

The total land area of Peninsular Malaysia is 132,078 $\mathrm{km}^{2}$ which is $40 \%$ of the total land area of Malaysia. The climate dictated by the two monsoons, the Southwest Monsoon from May to September and Northeast Monsoon from October to March, comes with high received rainfall.

One of the most prevalent deteriorations caused by this complicated interplay of materials and nature is corrosion. The environmental load is defined as the degradation agent from the atmosphere (i.e., gaseous pollution, acid deposition, and rainwater acidity) and its local climate (i.e., the relative humidity, temperature, and amount of received precipitation) [5]. Table 1 shows the air pollution emission in Malaysia as published in the Malaysian Statistical Handbook 2019 [6]. These substances will hasten the process of degradation. Degradation can be caused by bad behavior or stormy conditions, but the terminology of deterioration focuses on the deteriorating or weakening of a specific thing. The emitted air pollution increased over the years.

Table 1. Air pollution emission 2015 - 2019 in thousand tonnes [6].

\begin{tabular}{|c|r|r|r|r|r|}
\hline Type & 2015 & 2016 & 2017 & 2018 & 2019 \\
\hline $\mathrm{CO}$ & $1,759.2$ & $1,941.0$ & $2,123.3$ & $2,210.6$ & $2,235.1$ \\
\hline $\mathrm{NO}_{2}$ & 770.1 & 836.7 & 860.4 & 889.9 & 925.4 \\
\hline $\mathrm{SO}_{2}$ & 190.1 & 221.5 & 218.7 & 257.5 & 270.3 \\
\hline $\mathrm{PM}$ & 26.7 & 25.7 & 24.0 & 26.8 & 27.2 \\
\hline
\end{tabular}

When deterioration begins, the service life of the structure and its components is reduced. With a relative humidity of more than $50 \%$ and an average temperature of $27^{\circ} \mathrm{C}$, the average yearly time of wetness (TOW) in Peninsular Malaysia is 0.783 fractional hours [4]. The level of corrosion in Malaysia is categorized as class 5 by ISO 9223 , where the layer of moisture film on the

\footnotetext{
* Corresponding author: fathoni@uniten.edu.my
} 
surface of the metallic components can reside somewhat longer, and the deterioration process becomes more effective [7]. The most apparent effect of temperature is on the rate of the chemical reaction that results in degradation. Suppose their surface temperature goes below the dew point. In that case, the surface becomes moist and in the presence of corrosive pollutants, the concentrations of which are growing due to the stable influence of the temperature inversion, which is favorable to certain forms of material deterioration [8].

\subsection{Tower and lines assessment}

Energy infrastructure assessment is practically in place to ensure the reliability of the system to provide its service. Without an adequate understanding of deterioration processes, the effect of the defect to the other component of the tower, level or hazard of environmental exposure to the deterioration processes, a possible overlook on the existing condition of the tower will cause unexpected fault and failure.

Assessment outcome can be used to determine whether the component fits the assessment requirements. Each assessment method has a unique approach for collecting the results. Technical characteristic assessment is concerned with reporting the physical, mechanical, and qualities of a component that can be measured during scheduled patrolling activities using visual and assessment tools $[9,10]$. The main steps of condition assessment include recording any damage and determining the causes of distress, assessing the extent of distress, and estimating the residual strengths of structural components and the system [7-9].

\subsection{Health indices and predicted life}

Health index is being used to describe the overall condition of the transmission tower and transmission line. The scoring or condition rating from assessing components of a tower and its sub-components is calculated [1]. Weighing Scoring Method (WSM) with Analytical Hierarchy Processes (AHP) was used in determining the contribution of each component of high voltage transmission tower in Thailand [10]. The AHP is a multi-criterion analysis as mentioned in [12] used to determine the suitable weighting factor for each assessed component. The process of AHP starts with preparing a pairwise comparison matrix and assigning the scale of relative importance for each assessed component with respect to the other component to determine the tower's overall condition. The next step is to normalize the matrix and measure the consistency of the criteria weight using principle Eigen $\lambda_{\max }$ as in Equation (1) and the consistency index, $C I$ as in Equation (2).

$$
A w=\lambda_{\max }
$$

where $\mathrm{A}$ is an $n \times n$ non-negative matrix and $w$ is a weight vector as in the eigenvector method [12].

$$
C I=\frac{\lambda_{\max }-1}{n-1}
$$

where $n$ is the number of the category.
The prediction of service life and remaining life of a lattice steel transmission tower is discussed in [13]. The mean estimate of service life is 63 years with 21 years standard deviation depending on the climatic, environment, maintenance practices, quality of galvanizing, and paint regimes. It was mentioned that the ground condition affects the life of the foundation as well. A study on metallic building components in Malaysia where the service load and environmental load have been taken into consideration gave the service life of steel material's component ranged from 31 years to 45 years in the industrial area [14]. The statistical and probabilistic approaches were used to determine the residual and remaining life of the transmission tower [3, $11,15,16]$. In [3], the use of the Cox regression model of survival analysis model was used with respect to corrosion, which highly correlated deterioration due to climatic and atmospheric conditions.

\section{Method and materials}

In this study, the high voltage overhead transmission tower assessment was conducted on more than 80 towers in three different transmission lines. The nondestructive test and visual assessment were applied. The tower's condition was determined by eight parameters, i.e., corrosivity of the soil, chimney's condition representing the concrete part of the footing, galvanized steel member and the conductor, and the atmospheric corrosion level at the tower's location. Table 2 list the assessment method that was conducted on-site.

The level of deterioration is rated quantitatively in a range of numbers to measure the component's physical state. The ordinal numbers from 1 to 5 or 0 to 7 were used to reduce the likelihood of subjectivity in determining the level of performance due to too much detail distinguishing of specific components, with 1 being the worst condition and raising the number being the best condition. The description focuses on a quick write-up of the assessment, severity, and extent of any deterioration noticed. The description of the physical state would help in deciding on the rating and would also act as a crosscheck on the accuracy of the rating entry. A short description of the area where the tower is located was recorded as well. Photographs were recorded for validation purposes on the visual assessment data. Table 3 to Table 6 present the rating system that used in this study.

Table 2. Component of the tower and the assessment method.

\begin{tabular}{|l|l|c|}
\hline Component & Assessment & Scoring \\
\hline Soil & $\begin{array}{l}\text { The resistivity of soil, } \\
\text { based on ASTM G57 }\end{array}$ & $1-5$ \\
\cline { 2 - 3 } & $\begin{array}{l}\text { Ph, moisture, and } \\
\text { chemical content if } \\
\text { resistivity reading } \\
\text { below } 3000 \Omega \text {-cm }\end{array}$ & \\
\hline $\begin{array}{l}\text { Concrete } \\
\text { foundation }\end{array}$ & $\begin{array}{l}\text { Carbonation based on } \\
\text { CPC 18 }\end{array}$ & $1-5$ \\
\cline { 2 - 3 } & $\begin{array}{l}\text { Rebound hammer } \\
\text { based on ASTM C805 }\end{array}$ & $1-5$ \\
\hline
\end{tabular}




\begin{tabular}{|l|l|c|}
\hline & $\begin{array}{l}\text { UPV based on ASTM } \\
\text { C597 }\end{array}$ & $1-5$ \\
\cline { 2 - 3 } & $\begin{array}{l}\text { Visual assessment on } \\
\text { any related concrete } \\
\text { defect (i.e., crack, spall } \\
\text { out, delamination, etc.) } \\
\text { based on ACI 201, EN } \\
1504\end{array}$ & \\
\hline $\begin{array}{l}\text { Galvanized } \\
\text { steel member }\end{array}$ & $\begin{array}{l}\text { Visual assessment of } \\
\text { corrosion severity. }\end{array}$ & $1-5$ \\
\cline { 2 - 3 } & $\begin{array}{l}\text { The thickness of the } \\
\text { galvanize using } \\
\text { handheld elcometer. }\end{array}$ & $1-5$ \\
\hline Conductor & $\begin{array}{l}\text { The temperature at } \\
\text { fitting measured using } \\
\text { thermography camera. }\end{array}$ & $1-5$ \\
\hline $\begin{array}{l}\text { Atmospheric } \\
\text { corrosion level }\end{array}$ & Corrosion hazard map & $1-5$ \\
\hline
\end{tabular}

Table 3. Evaluation criteria for soil.

\begin{tabular}{|c|c|c|}
\hline Rating & $\begin{array}{c}\text { Resistivity } \\
\text { ohm } \mathbf{- c m}\end{array}$ & Corrosivity \\
\hline 5 & $>20,000$ & $\begin{array}{c}\text { Essentially non- } \\
\text { corrosive }\end{array}$ \\
\hline 4 & 10,000 to 20,000 & Mildly Corrosive \\
\hline 3 & 5,000 to 10,000 & $\begin{array}{c}\text { Moderately } \\
\text { corrosive }\end{array}$ \\
\hline 2 & 3,000 to 5,000 & Corrosive \\
\hline 1 & 1,000 to 3,000 & Highly corrosive \\
\hline
\end{tabular}

Table 4. Evaluation criteria for concrete in rebound hammer test.

\begin{tabular}{|c|c|c|}
\hline Rating & $\begin{array}{c}\text { Average } \\
\text { Rebound Number }\end{array}$ & $\begin{array}{c}\text { Quality of } \\
\text { Concrete }\end{array}$ \\
\hline 5 & $>40$ & $\begin{array}{c}\text { A very good hard } \\
\text { layer }\end{array}$ \\
\hline 4 & 30 to 40 & Good layer \\
\hline 3 & 20 to 30 & Fair \\
\hline 2 & $<20$ & Poor Concrete \\
\hline 1 & 0 & Delaminated \\
\hline
\end{tabular}

Table 5. Evaluation criteria for concrete in UPV.

\begin{tabular}{|c|c|c|}
\hline Rating & UPV (km/sec) & Concrete quality \\
\hline 5 & $>4.0$ & Very good \\
\hline 4 & 3.5 to 4.0 & $\begin{array}{c}\text { Good, but maybe } \\
\text { porous }\end{array}$ \\
\hline 3 & 3.0 to 3.5 & Poor \\
\hline 2 & 2.5 to 3.0 & Very poor \\
\hline 1 & 2.0 to 2.5 & $\begin{array}{c}\text { Very poor and low } \\
\text { integrity }\end{array}$ \\
\hline
\end{tabular}

Table 6. Evaluation criteria for corrosion of lattice steel tower [4].

\begin{tabular}{|c|c|}
\hline Rating & Description \\
\hline 7 & $\begin{array}{c}\text { New or Like New Condition. Galvanized } \\
\text { layer clearly intact with no or little rust. }\end{array}$ \\
\hline 6 & $\begin{array}{c}\text { Good Condition. Galvanized layer intact } \\
\text { and powdery rust evenly distributed. }\end{array}$ \\
\hline 5 & $\begin{array}{c}\text { Functioning as original design. The } \\
\text { galvanized layer is still partially intact with } \\
\text { few exposed spots on the steel } \\
\text { member/connection with no localized } \\
\text { corrosion. }\end{array}$ \\
\hline 4 & $\begin{array}{c}\text { Minimum Adequacy. Most of the } \\
\text { galvanized layer is corroded and leaving }\end{array}$ \\
\hline
\end{tabular}

\begin{tabular}{|c|c|}
\hline & $\begin{array}{c}\text { the steel exposed with an even layer of } \\
\text { rust. }\end{array}$ \\
\hline 3 & $\begin{array}{c}\text { Not Functioning as the original design. } \\
\text { Loss of steel section due to rust }(<1 \mathrm{~mm} \\
\text { for member). Some localized corrosion } \\
\text { takes place in partial depth. }\end{array}$ \\
\hline 2 & $\begin{array}{c}\text { Structurally Inadequate. Further loss of } \\
\text { steel section due to rust }(<3 \text { mm for } \\
\text { member) }\end{array}$ \\
\hline 1 & $\begin{array}{c}\text { Potential Hazardous. Loss of steel section } \\
(5 \text { mm for member). Steel corroded } \\
\text { throughout the member/connection. } \\
\text { Localized pitting is observed to full depth. }\end{array}$ \\
\hline 0 & $\begin{array}{c}\text { Dangerous. The steel section has corroded } \\
\text { to the full extend. Many pit holes are } \\
\text { found, and members can break off anytime. }\end{array}$ \\
\hline
\end{tabular}

The atmospheric corrosion level was published in a separate study. The corrosion hazard map was generated based on ten years' climate and air pollution data of wet deposition from 17 measurement stations in Peninsular Malaysia [4]. Figure 1. shows the location of 80 towers in the different transmission lines. In this study, a visual assessment on 8 members for each side of the tower was taken. The thickness of the galvanized Zink coating was measured at 32 points inside and outside the face of the lattice steel tower member.

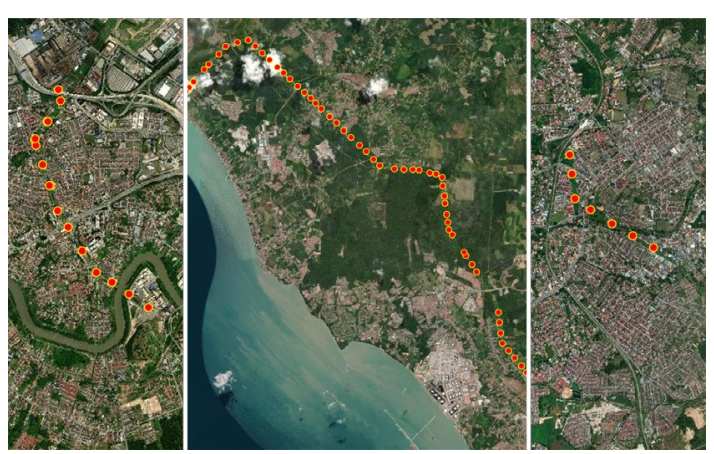

Fig. 1. Location of transmission tower in this study.

\section{Result and discussion}

\subsection{Corrosion}

Corrosion was the common sign of deterioration observed during the assessment. The corrosion was on the galvanized coating with no significant further corrosion to the carbon steel member. The galvanized Zink coating observed has more than 100 microns of thickness. Figure 2 shows the distribution of corrosion on tower members. It shows that corrosion is observed more often on redundant members with less slanted or flat-oriented members. There is $25 \%$ soil with high and highly corrosivity conditions recorded and affecting the concrete condition. Figure 3 shows the Partial correlation graph of soil corrosivity and concrete condition. 

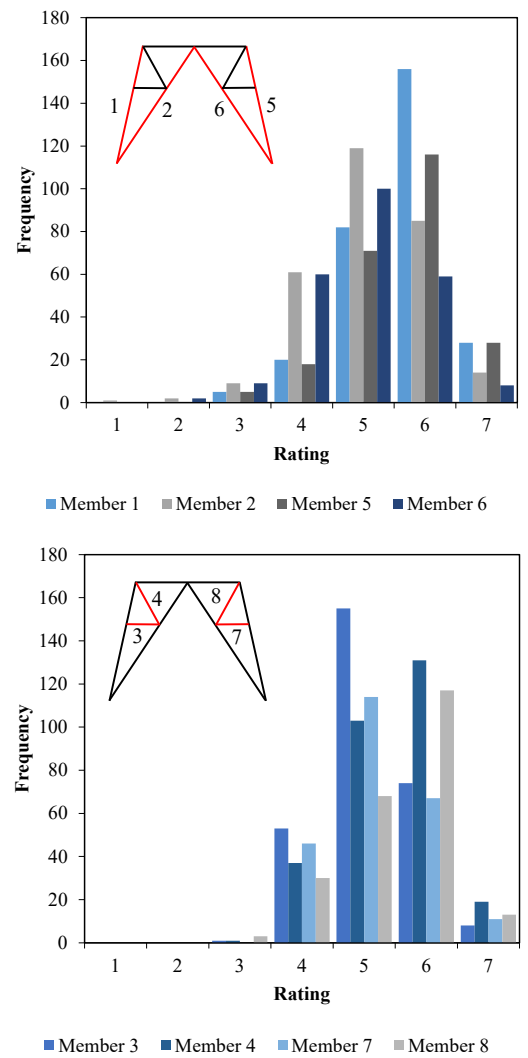

Fig. 2. Corrosion rating distribution for main member and bracing.

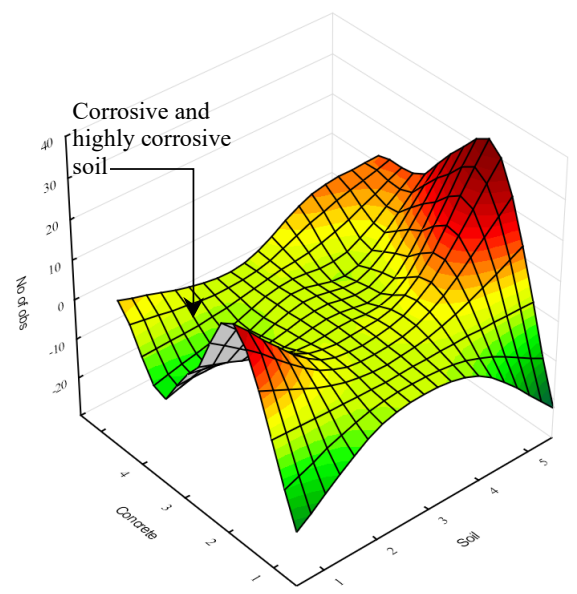

Fig. 3. Partial correlation graph of soil corrosivity and concrete condition.

\subsection{Predicted life}

The multi-criterion decision analysis with AHP produced weighing for each sub-component with $19.5 \%, 22.5 \%, 21.2 \%, 23.1 \%, 13.7 \%$ and the $C I$ of $0.084<0.1$. Figure 4 shows the linear fitting curve for the tower condition rating and age of the tower. It is found that the predicted age of a tower from this study can reach more than 70 years when it has a condition rating of 5 with an r-value of 0.5465 . The predicted life of a tower will gradually reduce by about 20 years for each decrease of the tower condition rating.

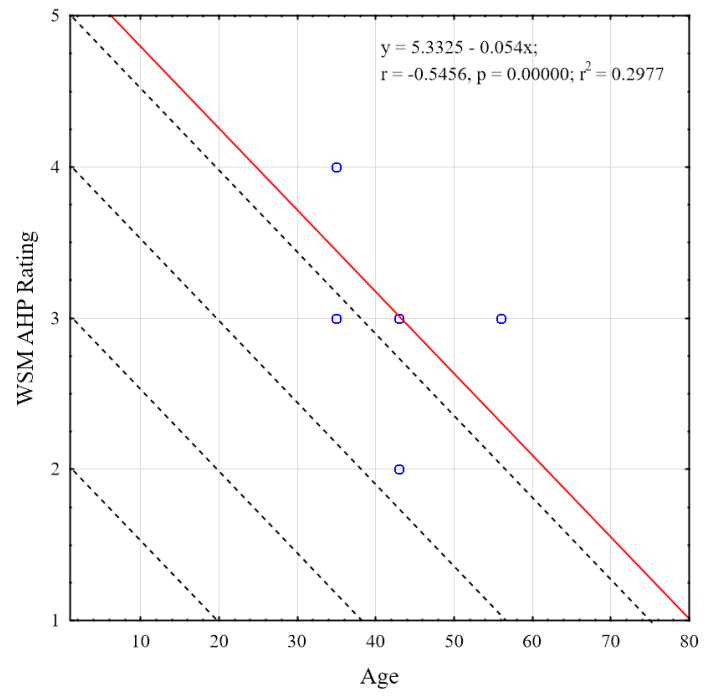

Fig. 4. Linear fitting of brushed data of condition rating and age of the tower.

The predictive remaining life of the lattice steel transmission tower in this study uses Kaplan-Meier survival analysis. The Kaplan-Meier model is based on estimating conditional probabilities at each time point when an event occurs to estimate the survival rate at each point in time. In the survival study, the tower condition rating and the age at which each rating is applied as the condition changes through time. Figure 5 shows the survival function plotted as a step function with the fitting curve of linear and quadratic mode. Visually, the range of predicted life of the tower from the survival function seems to be a good approximation of 60 to 78 years.

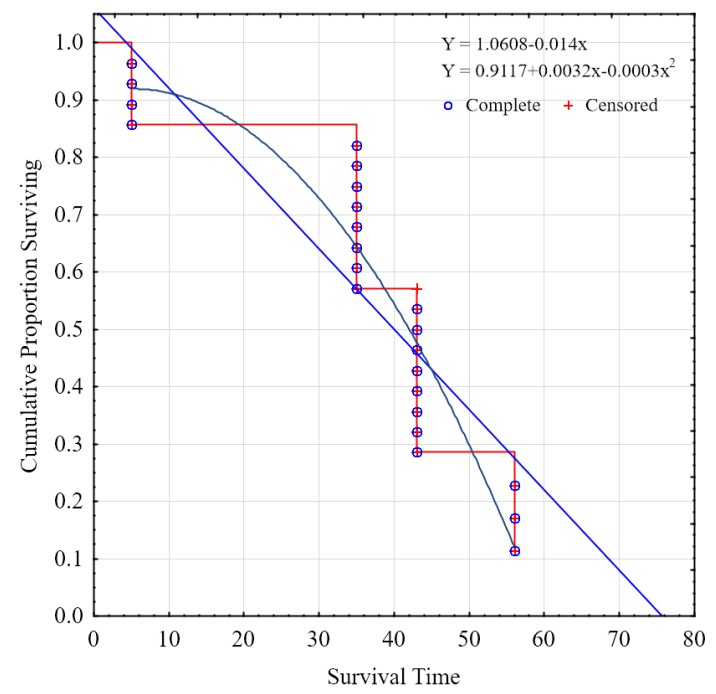

Fig. 5. The survival function plotted as a step function with fitting curve of linear and quadratic mode.

The Kaplan-Meier model is used when the expression of the baseline hazard is unknown, and it is just estimated at points in time where one or more reductions of the physical state of the tower have occurred. The tower's mean residual or remaining life (mrl) can be predicted using the fitting equation as in Equation 3. 


$$
m r l=\frac{\int_{t}^{\infty} F(x) d x}{F(x)}
$$

where $t$ is the age of the tower.

The $m r l$ value from the survival function can be used by the maintenance unit of the asset management team to strategize and plan the frequency of inspection at a specific location and replacement of components in advance.

\section{Conclusion}

This paper presents assessments conducted on high voltage transmission towers at three different transmission lines. The Weighing Scoring Method (WSM) with multi-criteria decision analysis using Analytical Hierarchy Processes (AHP) was implemented to determine the tower condition rating. From the assessment, it was observed that higher corrosion occurred on more flattened members than slanted members. The soil corrosivity affects the concrete condition of the tower foundation. The KaplanMeier model of survival analysis was utilized in this study, and the tower's service life was estimated to be between 60 and 78 years. The remaining service life can be calculated using the mean residual life ( $m r l)$ that can be used to plan and strategize the maintenance and replacement works.

\section{References}

1. R. Hashim, F. Usman, and I. N. Z. Baharuddin, Resources 8, 2 (2019)

2. Tenaga Nasional Berhad, Integrated Annual Report 2020, Kual Lumpur (2020)

3. M. Segovia et al., Predicting remaining life of transmission tower steelwork components, in Proceeding of the $26^{\text {th }}$ Eur. Saf. Reliab. Conference. ESREL (2017)

4. F. Usman, N. H. N. Khalid, R. C. Omar, and M. J. A. Jawas, Atmospheric corrosion map for service life prediction of lattice steel tower using air pollution data and meteorological data, in AIP Conference. Proceeding 2339, 020189 (2021)

5. J. I. Silva Filho, L. A. M. C. Domingues, A. P. Ruffier, and A. A. Menezes, Assessment of environmental statistics as an accessible breakthrough to improve OHTLS design, in Proceeding of $41^{\text {st }}$ Int. Conf. Large High Volt. Electr. Syst. 2006, CIGRE (2006)

6. Department of Statistics Malaysia, Malaysia Statistical Handbook 2019, October. Jabatan Perangkaan Malaysia (2019)

7. U. Fathoni, C. O. Rohayu, and C. M. Zakaria, Environmental Zoning for Service Life Prediction of Building Components in Malaysia, in Proceeding of IOP Conf. Ser. Earth Environ. Sci., 16, 1 (2013)

8. J. J. Santana et al., Metals (Basel) 9, 10, (2019)
9. A. I. Wuller and A. Pharmatrisanti, Transmission line assessment, in Proceedings of 2012 IEEE International Conference on Condition Monitoring and Diagnosis, CMD 2012, September (2012)

10. Waraporn, Luejai, S. Thanapong, and S. Cattareeya, Condition evaluation of high voltage transmission line in Thailand, in Lecture Notes, in Electrical Engineering 598: Proccedings of the $21^{\text {st }}$ International Symposium on High Voltage Engineering, Budapest (2017)

11. A. Van Der Wal, A. A. H. J. Ross, and T. D. C. Kema, CIGRE Sess. B2-204 (2004)

12. J. A. Alonso and M. T. Lamata, Int. J. Uncertainty, Fuzziness Knowlege-Based Syst. 14, 4 (2006)

13. CIGRE Working Group 37.27, Ageing of the system - impact on planning, in Session 2000 (2000)

14. F. Usman and Resdiansyah, Service life prediction of building components, in ICCBT - International Conference on Construction and Building Technology, Malaysia (2008)

15. A. A. H. J. Ross, B. Rhebergen, and V. A. N. O. J. P. M, Probabilistic based condition assessment of overhead transmission lines, CIGRE, France (2000).

16. J. Haque, U. Chandra, S. K. Agrawal, P. Kumar, and $\mathrm{H}$. Vyas, Use of statistical tools for assessment of residual life of transmission linesviz-a-viz steps taken to augment the reliability of transmission network of powergrid (India), in Proceeding of $41^{\text {st }}$ International Conference on Large High Voltage Electric Systems 2006, CIGRE (2006) 